\title{
Prevalence of Enzootic Bovine Leukosis in Bulgaria
}

\author{
Nikolay SANDEV ${ }^{1}$, Darinka ILIEVA², Nikolina RUSENOVA ${ }^{1}$, Valentina MARASHEVA ${ }^{2}$ \\ ${ }^{1}$ Faculty of Veterinary Medicine, Trakia University Stara Zagora, BulgariaNational \\ ${ }^{2}$ Diagnostic and Research Veterinary Medical Institute Sofia, Bulgaria. \\ Corresponding author: n_sandev@abv.bg
}

Bulletin UASVM Veterinary Medicine 72(1) / 2015,

Print ISSN 1843-5270; Electronic ISSN 1843-5378

DOI:10.15835/buasvmcn-vm: 10521

\begin{abstract}
The Enzootic bovine leukosis (EBL) is broadly spread on all continents. Due to the lack of specific means for prevention and treatment, it turns to be a serious health and economic issue for a number of countries with developed cattle farming. The aim of the present study was to establish the prevalence of EBL in Bulgaria in 2012 and the effect of the application of the State Programme for Infection Prevention and Control. Official data from the annual report of the Bulgarian Food Safety Agency (BFSA) and serological analyses for enzootic bovine leukosis conducted with commercial ELISA kits was employed. The results were statistically analysed using the method for comparison of independent proportions. The analysis of results from serological EBL survey performed in 2012 showed a high prevalence of the infection in Bulgaria (33.38\% on the average) and more than 2000 foci. In the different regions of the country, the proportion of infected animals varied from $13.05 \%$ to $63.85 \%$. After implementation of the mandatory measures for enzootic bovine leukosis prevention and control, one region was completely freed from enzootic bovine leukosis and 78 infection foci were eradicated. The results from the serological analyses for enzootic bovine leukosis performed in 2012 showed a wide prevalence of the infection in Bulgaria. The successful eradication of cattle farms is possible with strict implementation of the State Programme for EBL Prevention and Control and co-funding by the European Community.
\end{abstract}

Keywords : ELISA, enzootic bovine leucosis, eradication, prevalence.

\section{INTRODUCTION}

Enzootic bovine leukosis (EBL) is a chronic viral infection accompanied by quantitative and qualitative changes in B-lymphocytes, macrophages and endothelial cells, followed by hyperplastic proliferative events in haematopoietic organs. The disease is caused by the bovine leukosis virus, which belongs to genus Deltarethrovirus of the Retroviridae family. The virus suppresses the immune system, resulting in poorer systemic resistance and increased metritis, mastitis, arthritis and pericarditis incidence (Rulka et al., 1993; Rusov et al., 1994; Sandev et al., 2005). All this has an impact on the productivity and efficacy of livestock husbandry and is directly associated with the economic status of dairy cattle farms (Kostadinova, 2003; Kuzin et al., 1997; Kuznetsov et al., 1993; Sandev et al., 2000; Tsutsumanski, 1999; D' Angelino et al., 1998).
The disease is broadly spread on all continents. Due to the lack of specific means for prevention and treatment, it is a serious health and economic issue for a number of countries with developed cattle farming (USA, Japan - Murakami, 2009; Murakami et al., 2011; Canada - Chi et al., 2002; Brazil - D`Angelino et al., 1998; Argentina - Gonzalez et al., 2007; Columbia - Betancur et al., 2008; Turkey - Burgu et al., 2005; Israel Trainin et al., 2005; Iran - Mohammadi et al., 2011, Kazemimaesh et al., 2012; Australia - Ryan, 2013; RSA - Ndou et al., 2011).

As a result from the implementation of efficient eradication programmes, most EC countries are formally free of leukosis except for some regions in Portugal, Italy and Poland. The disease is yet widely prevalent in Greece, the Republic of Cyprus, Bulgaria, Hungary and Estonia (Sanco, 2013). 
The aim of the present study was to establish the prevalence of EBL in Bulgaria in 2012 and the effect from the application of the State Programme for Infection Prevention and Control.

\section{MATERIAL AND METHODS}

The annual report of the Bulgarian Food Safety Agency (BFSA) with data from serological analyses for enzootic bovine leukosis conducted with commercial ELISA kits ID Screen BLV Indirect produced by ID. Vet - France with standardized antigen and serum approved by the was employed. The results were statistically analysed using the method for comparison of independent proportions.

\section{RESULTS AND DISCUSSION}

The results from serological studies (Tab. 1) showed that the number of individual blood serum samples from cattle assayed in 2012 was 235,811 and that out of them 78,717 or $33.38 \%$ were positive for enzootic leukosis. This showed that EBL was widely prevalent in the country, with 2,062 foci in 27 out of 28 districts. In comparison with 2009 , the proportion of seroreagents increased by $11.29 \%$ (Sandev et al., 2010). Throughout the year, 3,963 seropositive animals or $5.03 \%$ of infected cattle were condemned, and another $17(0.02 \%)$ have died. Seventy-eight infection foci $(3.78 \%)$ were eradicated. By the end of 2012, the number of infected animals was 74,731 in 1,984 foci. Only in the region of Smolyan, where the seroreagent percentage in 2009 was $0.25 \%$, the disease was completely eradicated (Fig. 1). In the other regions of the country, the incidence of positive seroreagents varied from $13.05 \%$ in Kardzhali to $63.85 \%$ in Montana. In some regions (Razgrad, Targovishte, Vidin, Plovdiv) the number of infected animals increased several times as compared to 2009, while in others (Rousse, Haskovo, Burgas, Kyustendil, Pleven) there was a tendency towards decrease. The most numerous EBL foci were in the region of Burgas (162), followed by Stara Zagora (152) and Shoumen (149), and the fewest - in the region of Sofia (10), Pazardzhik (22) and Kyustendil (31). With regard to the geographical prevalence of the infection, it was more frequently seen in North Bulgaria than in South Bulgaria.

In Bulgaria since 2012, a single serological analysis for EBL is performed on all cattle 12 months of age which have not been screened during the previous years and originated from farms in category I and II. Also, serological analysis is performed on all bovines older than one year from category I and II farms, which were negative for EBL during the previous year. All animals positive for EBL are obligatorily excluded from breeding and condemned. In case of pregnant animals, there are left until calving. all calves born by seropositive cows are fattened and slaughtered. An exception is made only for calves born by seropositive dams, if since its birth the calf is reared separately and fed milk from a healthy cows or a milk replacer. Blood serological analysis is done once on all cattle older than 12 months of age, imported in Bulgaria from third countries for breeding during the obligatory quarantine period. The results of assays are entered in the integrated information system of the Bulgarian Food Safety Agency.

The analysis of results from the serological survey in 2012 showed that despite a State Prevention and Control programme was developed, it was only partially implemented. For years, there is almost no progress in eradication of leukosis from cattle farms. The main cause for the poor results in EBL control in our opinion is the lack of adequate financial support of the programme. Unlike the majority of East Europe member countries, Bulgaria, Romania and Hungary have not received a financial support for EBL eradication so far. Nevertheless, the epidemic situation with respect to bovine leukosis in Romania is very different. As a result from the strict implementation of the state prevention programme, only for 3-year period from 2003 to 2005, the number of EBL foci was reduced from 611 to 135 (22.09\%) (Hiottu et al., 2006), and the proportion of seropositive animals - from $0.76 \%$ in 2003 to $0.54 \%$ in 2004 .

The control of EBL is a hard and slow process, dependent on a number of objective and subjective factors. The main tool for infection control could be EC funds for support of dairy producers, which could be higher for farms free of the EBL virus. This would stimulate the active cooperation between farmers and veterinary authorities during EBL eradication. In farms with single cases of leukosis, infected animals are excluded from breeding and are condemned. In foci with seroreagents prevalence lower than 5.0\%, the eradication model used in Spain and Romania for creation 
Tab. 1. Prevalence of EBL in Bulgaria in 2009 and 2012.

\begin{tabular}{cccccccccc}
\hline Year & Number & $\begin{array}{c}\text { Number } \\
\text { positive }\end{array}$ & $\begin{array}{c}\text { Percentage } \\
\text { positive }\end{array}$ & $\begin{array}{c}\text { Number } \\
\text { of foci }\end{array}$ & $\begin{array}{c}\text { Number } \\
\text { and } \\
\% \text { dead }\end{array}$ & $\begin{array}{c}\text { Number and } \\
\% \text { slaughtered } \\
\%\end{array}$ & $\begin{array}{c}\text { Number } \\
\text { infected }\end{array}$ & $\begin{array}{c}\text { Number/\% } \\
\text { cured foci }\end{array}$ & $\begin{array}{c}\text { Number } \\
\text { still infected } \\
\text { foci }\end{array}$ \\
\hline 2009 & 338944 & 74879 & 22.09 & 2035 & - & - & 74879 & - & 2035 \\
\hline 2012 & 235811 & 78711 & 33.38 & 2062 & $17 / 0.02$ & $3963 / 5.03$ & 74731 & $78 / 3.78$ & 1984 \\
\hline
\end{tabular}

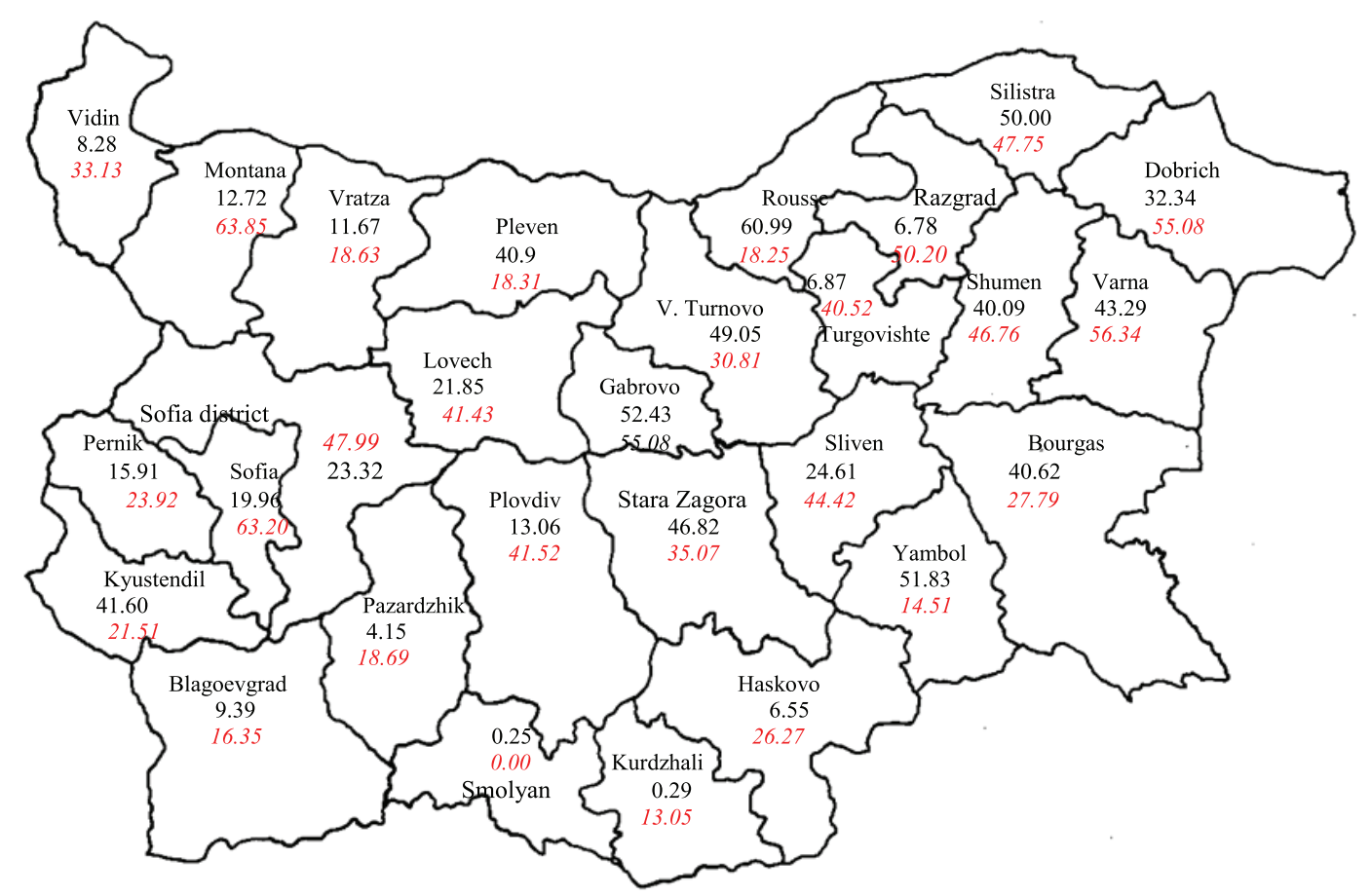

Fig.1. Prevalence of EBL in Bulgaria in 2009 and 2012 per districts (in \%). The results for 2012 are given in Italic.

of EBL virus free areas could be applied. In foci with high prevalence of seropositive animals, affected cattle should be isolated in a separate premise, with separate personnel, without contact with healthy cattle, and should be directed to the slaughterhouse on a periodical basis.

In cattle farms free from the leukosis virus, ELISA analysis for antibodies of bulk milk samples is advised once in a year. If a positive sample is detected, serological survey of individual blood samples should be done to identify infected animals and exclude them from breeding.

In conclusion, it should be emphasized that the eradication of EBL in Bulgaria is possible with strict implementation of the State Programme for EBL Prevention and Control and co-funding by the European Community.

\section{CONCLUSION}

The results from the serological analyses for enzootic bovine leukosis performed in 2012 showed a wide prevalence of the infection in Bulgaria. The average proportion of seropositive reagents was $33.38 \%$ varying within a range from $13.05 \%$ to $63.85 \%$.

The successful eradication of cattle farms is possible with strict implementation of the State Programme for EBL Prevention and Control and co-funding by the European Community.

\section{REFERENCES}

1. Betancur C, Rodas J (2008). Seroprevalencia of bovine leukemia virus in animals with reproductive problems in monteria. Rev Med VZ Cordoba 13(1):1197-1204.

2. Burgu I, Alkan F, Karaoglu T, Bilge-Dagalp S, Can-Sahna K, Gungor B, Demir B (2005). Control and eradication programme of enzootic bovine leucosis (EBL) from selected dairy herds in Turkey. Dtsch Tierarztl Wochenschr 112 (7):271-274. 
3. Chi J, Van Leeuwen J, Weersink A, Keefe G (2002). Direct production losses and treatment costs from bovine viral diarrhoea virus, bovine leukosis virus, Mycobacterium avium subspecies paratuberkulosis and Neospora caninum. Prev Vet Med 55:137-153.

4. D Angelino J, Garcia M, Birgel E (1998). Epidemiological study of enzootic bovine leukosis in Brasil. Trop Anim Health and Prod 30:13-15.

5. D' Angelino J, Garcia M, Birgel E (1998). Productive and reproductive performance in cattle infected with bovine leukosis virus. J Dairy Res 65:693-695.

6. Gonzalez T, Licursi M, Bonzo E (2007). Enzootic bovine leucosis: performance of an indirect ELISA applied in serological diagnosis. Braz J Microbiol 38(1):1-8.

7. Hiottu A, Nicolae S (2006). Enzootic bovine leukosis eradication in Romania, in 2003-2005 using in Romanian sanitary veterinary legislation the C. E. E. recommendations. Slov Vet Res 43(10):289-290.

8. Kazemimanesh $\mathrm{M}$, Madadgar $\mathrm{O}$, Mahzoonieeh $\mathrm{MR}$ Zahraei-Salehi T, Steinbach F (2012). A Serological study on bovine leukemia virus infection in ten provinces of Iran between 2010 and 2012. Iran J Virol 6(3):1-7.

9. Kostadinova N (2003). Economic Aspects of Veterinary Service in Bulgaria, USA and Other Countries. Iskra M-I Publishing House, Stara Zagora, 24-26.

10. Kuzin A,d Zakrepina E (1997). Effect of bovine leukosis on cow performance and milk quality. Veterinaria 2:19-21.

11. Kuznetsov A, Nikitin I (1993). Economic losses caused by enzootic bovine leukosis. Veterinaria 8:14-16.

12. MohammadiV,Atyabi N, Nikbakht Brujeni Gh, Lotfollahzadeh S Mostafavi E (2011). Seroprevalence of Bovine Leukemia Virus in Some Dairy Farms in Iran. Global Veterinaria 7(3):305-309.

13. Murakami K (2009). Enzootic bovine leukosis (EBL) and recent prevalation and control measurement in Japan. Yam J Vet Med, 36:5-29.
14. Ndou R, Sejesho F, Dzoma B, Motsei L, Nyirenda M, Bakunzi F (2011). A Serosurvei of the Prevalence of Enzootic Bovine Leukosis in thr Mafikeng Area of the North West Province of South Africa. J Hum Ecol, 36(1):53-55.

15. Rulka J, Dacko J, Kozaczynska B, Reichert M, Klimentowski St(1993). Milk production of cows infected with enzootic bovine leukaemia virus evaluated on the basis of the ELISA and AGID tests. Medycina Veterynaryjna 49(9): 408-411.

16. Rusov C, Milojevic Z, Stojanovic L (1994). Occurrence of mastitis and sanitary-hygienic quality of milk of cows infected with enzootic leucosis. Veterinarski glasnik 48:34, 303-308.

17. Ryan D (2006). Eradication of enzootic bovine leucosis in national dairy herd. Flock and Herd,1-5.

18. Sanco 2013/10941. Summary report on the outcome of EU co-financed animal disease eradication and monitoring programmes period 2007-2011, 55-58.

19. Sandev N, Kostadinova N, Zarkov I (2000). Economic aspects of bovine leucosis, Agricultural Economy and Management. 1:38-41.

20. Sandev N., M. Koleva, R. Binev and T. Iliev (2005), Effect of enzootic bovine leukosis virus on milk yield and subclinical mastitis incidence in cows at different stages of infection, BJVM, 8, Suppl. 1, 37-41.

21. Sandev N, Ilieva I, Iliev E, Russenova N, Hvarchilkov V (2010). Studies on the prevalence of enzootic bovine leukosis in Bulgaria during 2005-2009. XXth Jubilee rnational Scientific Conference, St. Zagora, Bulgaria. Proceeding Book I:53-57.

22. Trainin Z, Brenner J (2005). The direct and indirect economic impacts of bovine leukemia virus infection on dairy cattle. Isr J Vet Med 60(4):94-105.

23. Tsutsumanski V (1999). Epizootological evaluation of enzootic bovine leukosis prevention and control in conditions of modern livestock husbandry. VM News 3:15-17. 